\title{
Review
}

Fertility preservation in Turkey: a global look for nationwide strategy development

\section{Hatırnaz et al. Fertility preservation in Turkey: a global look for nationwide strategy development}

Şafak Hatırnaz', Kadir Bakay², Ebru Hatırnaz', Davut Güven², Alper Başbuğ $\breve{g}^{3}$, Önder Çelik ${ }^{4}$, Gazi Yıldırıms, Cihat Ünlǘ

In Vitro Fertilization-IVM Center, Medicana Samsun International Hospitål, Samsun, Turkey

Department of Obstetrics and Gynecology, Ondokuzmayıs University School of Medicine, Samsun, Turkey

Department of Obstetrics and Gynecology, Düzce University School of Medicine, Düzce, Turkey

Private Office, Uşak, Turkey

Department of Obstetrics and Gynecology, Yeditepe University Faculty of Medicine, İstanbul, Turkey

Department of Obstetrics and Gynecology, Acıbadem University Faculty of Medicine, İstanbul, Turkey

Adress for Correspondence: Şafak Hatırnaz

Phone: +90 5332372922 e-mail: safakhatirnaz@gmail.com

\section{DOI: 10.4274/jtgga.2018.0116}

Received: 31.08 .2018

Accepted: 09.02.2019

ABSTRACT

Objective: As the reproductive technology advanced along with the improved outcome in cancer treatment demands implementing new fertility preservation. Developing algorithms on fertility preservation requires tailoring for each society. Here authors attempts to modify the current medical literature on fertility preservation for Turkish population.

Materials and Methods: Pubmed search was conducted using the term fertility preservation as the keyword. Initially, 280 items of literature have been accessed. In second evaluation 126 articles examined 154 items were discarded due to low quality of the literatures.In the final round, only 68 publications which are the most relevant were found eligible to include in the review article.

Results: In order to develop a more systematic national guideline, forming a multidisciplinary approach to create a web based network would be the first step. Both physicians and patients will have an open access to the information. This database should be linked to international consortium to stay integrated and open to update. 
Conclusion: The aim of this review is to evaluate the relationship between the current situation in our country and the developments in the world in the light of literature, and to establish the infrastructure for the development of future approaches in our country Keywords: fertility preservation, oncofertility, oocyte -embryo freezing, treatment modalities, national program

\section{Introduction}

We, as doctors, must always keep in our minds the basic message from the hippocratic oath 'primum non nocere'. However, every medical or surgical treatment carries certain degrees of side effects or complications which may cause the deterioration of some functions while improving the other ones. Tremendous advances in medical diagnosis and therapy have increased the survival rates in children and young age women with malignancies. Thus, fertility preservation has become a must in the routine practice of oncology(1). This necessitates the consultations with reproductive endocrinologists before and after the oncological treatment(2). Since the demand of consultation for fertility preservation became a matter, developed countries started to arrange guidelines and established organizations and societies related to oncofertility and fertility preservation. Oncofertility consortium(OC), supported by National Institute of Health(NIH) was founded in 2007; and evolved as the biggest organization to improve the fertility expectations of patients with cancer and medical professionals dealing with oncofertility worldwide (3).19 countries are involved in the OC but only 6 organizations actively contributed to the $\sigma C$ and others remained inactive. FertiPROTEKT, a strong organization for fertility preservation in Europe, expanded the indications and added severe rheumatic diseases and social indications and developed strategies and guidelines and recommendations for those diseases too (4). Indications for fertility preservation apart from oncofertility include premature ovarian failure due to genetic reasons and autoimmune disorders like Diabetes mellitus, thyroid dysfunction, Addison Syndrome, Myasthenia Gravis, Crohn's Disease,Lupus and rheumatoid arthritis (5).

Oncofertility can be défined as a new discipline hosting many medical and social disciplines in it and aims to give cancer survivors an opportunity to preserve their potential to have baby. Fertility preservation is the efforts to preserve cancer patient's potential by either surgical methods or medical methods to obtain oocytes or embryos for future use (6).

Current situation in Turkey is confusing. Turkey seems to be a member of OC but she is not actively involved in the OC activities. Oncofertility is an issue that finds place in gynecological oncology and infertility congresses; but not more than that. There exists no official organization or a society that deals specifically with fertility preservation. There appears to be no web-based program that will inform the patients and medical professionals who deal with fertility preservation.

This review article aims to refresh the current knowledge on fertility preservation methods and to recommend what can be done in order to have a nationwide fertility preservation program in Turkey. 


\section{Materials and Methods}

A pubmed search was conducted using the term fertility preservation as the keyword. About 280 items of literature have been accessed and 126 of these literature items were subjected to a second evaluation. 68 publications were included in this review study.

\section{Discussion}

Oncofertility is a multidisciplinary approach, and if it can be implemented in the same institution, it could be of great benefit. However, this is not a convenience that can always be present in all the institutions at all times. Disorganization as well as detachment between the disciplines seems to be one of the fundamental problems related to the preservation of fertility. Another significant point is concerned with the evaluation of how much sensitivity physicians working in the field of oncology have. For this purpose, a pilot study conducted in the USA in 2009 revealed highly striking results. $61 \%$ of the oncologists who participated in the survey stated that they always or most of the time explained the effects of oncological treatments on fertility to their patients but $45 \%$ of the physicians indicated that they did not refer their patients to an infertility specialist. The sensitivity of physicians who have previously attended a seminar on the subject matter of fertility preservation is higher than those who have never participated in such seminars (45\% and 33\%, respectively). While 55\% of the physicians who participated in a seminar recommend an administration of a less aggressive chemotherapy, this rate has been determined to be $29 \%$ for those who have not taken part in seminars. Patient attitudes, bad prognosis and immediacy required for the initiation of treatment seem to be the leading reasons why physicians are insensitive towards this issue. It is possible to consolidate the bridge between oncologists and infertility specialists further through increasing number of trainings as well as approaches that are geared towards enhancing sensitivity. Thus, fertility can be preserved in young cancer patients whose survival rate has increased (7). A survey study conducted among the hematologists in Turkey inquired the attitudes and behaviors of hematologists about the preservation of fertility. 25 physicians were contacted, and it was observed that all the hematologists showed sensitivity towards fertility preservation, however, $8 \%$ of the participants stated that they were not aware of fertility preservation at all. $76 \%$ of them pointed out that they did not have sufficient knowledge of the subject matter. $88 \%$ of the physicians who responded to the survey stated that they wanted to be informed more about fertility preservation, while $23 \%$ put forth that a written brochure or written resource would be required on this subject matter. All the participating hematologists agreed upon the recommendation that Turkish Hematology Association prepare a guideline on the subject and a session on fertility preservation in the congresses be held on regular basis (8).

Differences in the physicians' attitudes and behaviors pose an obstacle to the options for fertility preservation in cases where hematopoietic stem cell transplantation (HTC) has been implemented. Accordingly, an invitation was sent to 1035 physicians in the USA, and only 185 of those physicians responded to the survey which comprised 29 question items. It was revealed that the responding physicians had awareness as to the preservation of fertility, and having discussions over fertility preservation made them feel better. Yet, it was found out that only $55 \%$ of them referred their patients to an 
infertility specialist. $63 \%$ of the participating physicians pointed out that their patients were so ill that they were not in the position of being able to postpone the transplantation. It was also maintained that the patients had natural barriers; like they were already infertile during the onset of the treatment (92\%). The study revealed that demographic attributes of the physicians, their knowledge and perception on the subject matter had predictive significance with regard to referring the patients for the preservation of fertility (9).

Following the pilot study, Forman et al. carried out a survey across the USA in 2010 . They sent a questionnaire form to the oncology physicians three times in one year over the web based surveymonkey system, requesting online responses from the participants of the survey. They received the responses of 249 physicians out of 1701 questionnaires sent. $95 \%$ of the physicians said that they discussed fertility preservation with their patients. Even though $82 \%$ of the physicians stated that they referred the patients to an infertility specialist, only half of those patients performed such a consultation. $30 \%$ of the physicians stated that they acted in an indifferent way regarding fertility while planning the treatment. It was observed that gynecologic oncologists attach much more importance to fertility compared to medical oncologists. In similar vein, gynecologic oncologists consider preserving fertility by planning less aggressive treatments. The rates of oncologists referring patients in academic hospitals are much fewer when compared to gynecologic oncologists. According to oncologists, patients can take the chance of having a $5 \%$ reduction in their survival rates for the preservation of their fertility (10).

New diagnoses and treatments emerge as a result of increasing genetic and epigenetic studies as well as the revealing of human genome (11). It is known that male infertility increases the risk of developing cancer in the future. The same applies for female infertility as well. Besides this, it is also thought that the medications used for female infertility may increase cancer risk. It is believed that infertility and cancer have common predispositions in terms of genetic and epigenetic aspects. Apart from these, common environmental factors also play a role in exacerbating these problems. Hanson et al. studied that male infertility carries the risk of developing testicular cancer, bladder cancer and thyroid cancer, as well as lymphoma and leukemia. They also observed that such a risk would also apply for their close relatives, concluding that a genetic common predisposing element triggered in germline could be existent (12). Nagirnaja et al. studied the genetic links between cancer and infertility, examining the known oncogenes and important genes in spermatogenesis. They inquired whether there is a link between these, having concluded that extensive genomic studies should be performed, and susceptible locations should be identified related to both infertility and cancer through germline scanning (13). James et al. determined that epigenetic changes in male infertility and cancer increase susceptibility for these two pictures. They also drew the conclusion through the two hit hypothesis that one epimutation causes infertility, while the other one leads to cancer (14).

A significant increase in the life expectancies of cancer patients at young age has been observed owing to the novelties in treatments. The most frequently seen cancer types among young individuals aged 15-24 in Europe are Hodgkin's lymphoma, testicular cancer and malignant melanoma (15). 5 years of survival among the young patients is 
above $90 \%$. The most commonly observed forms of cancer seen among adults aged 25-49 are breast cancer, colorectal carcinoma, cervical cancer and malignant melanoma (16). The most frequently encountered malignancy among those aged below 35 in the UK is breast cancer. Mortality rates in breast cancer patients aged under 50 have decreased significantly through the polychemotherapy approach. Nonetheless, aggressive chemotherapy and radiation therapy administrations are lamentably required for many cancer types encountered frequently, which may cause permanent damage of the reproductive functions (17). This situation accompanies many other ones that have to do with quality of life apart from the loss of fertility, including osteoporosis, depression, cognitive disorders, cardiovascular diseases and sexual dysfunction. There is an increasing amount of interest in fertility preservation both among oncologists and also among reproductive endocrinologists and infertility specialists, which have brought about the production of many new treatment strategies. Preservation of fertility as a multidisciplinary approach was put on the agenda in the 2009 EVAR (Evian Annual Reproduction) Meeting (18).

No evidence exists as to the direct impact of cancer on the reproductive system, yet treatments thereof may bring about adverse effects in several locations. For instance, in cases with the entire body exposed to radiation therapy during childhood with doses of 14-30 Gy, it is known that uterine growth and development slows down (19). Administration of uterine radiation therapy during childhood and young youth period causes the increase in the frequency of miscarriage and Intrauterine Growth Restriction (IUGR) in the future (20). The risks of acute ovarian insufficiency, premature ovarian insufficiency, premature menopause, low ovarian volume and being of low weight in newborn babies were observed to be increased among cancer patients that were exposed to radiation therapy and /or chemotherapy administered with alkylating agents (21). As for chemotherapy and radiation therapy, the target cells in the ovary are follicular; and this causes a huge amount of reduction in the follicles. Besides this, based on this situation, endocrine and reproductive functions deteriorate. The decreased primordial follicular pool raises the probability of ovarian insufficiency and premature menopause probability (17). The lethal dose for primordial follicles is $2 \mathrm{~Gy}(22)$. The gonadotoxic medication impact in the ovary causes a vicious cycle and since the breakdown of primordial follicles reduces the secretion of estradiol and inhibin, FSH release increases, which in turn leads more follicles to enter the cohort, causing much more follicular damage as a consequence (23). This point reveals that more sensitivity is required to be shown in the approach towards female patients with regard to the preservation of fertility. Premature ovarian insufficiency emerges at further ages and persistent amenor is accepted as a marker of ovarian insufficiency (24 ). Checking the number of antral follicles (AFC) and antimullerian hormone (AMH) before the initiation of the treatment and doing the follow-ups in the post-treatment period can be used as a marker for the detection of the harms of gonadotoxic treatment (25).

Radiation therapy and chemotherapy applied on the pelvic or spinal location is gonadotoxic and toxicity is concerned with either the mode of treatment or the relevant dosage of the treatment (26). Chemotherapeutic agents are generally used in combination so as to benefit from their synergic effects and to achieve a more effective result on the tumor. The agents known to be the most gonadotoxic are with an 
alkylating agent, and they increase the cyclophosphamide toxicities in taxanes used in adjuvant treatments (27). Radiation therapy-induced damage is based on the dose, area of treatment and frequency of its administration (20 Wallace 2005).

The highest gonadotoxicity is seen in cases where intensive combined chemotherapy and entire body radiation therapy are applied prior to bone marrow transplantation, in cases of metastatic Ewing sarcoma and soft tissue sarcoma as well as in Hodgkin lymphoma where alkylating agents are used (28).

Preservation of fertility should be recommended to young cancer patients as early as possible, yet cancer treatment may take precedence over fertility preservation most of the time (29). What is recommended is to have the patient consult with an infertility specialist and inform the patient accordingly as to fertility preservation so that the issue can be cleared up (30). If there is possibility and ample time for medical treatment, it could be tried out. If no such convenience is present, then fertilitypreserving cancer treatments should be considered. Fertility remains intact if medical treatment is administered in endometrial cancer or conservative modes such as radical trachelectomy are administered in the early phase of cervical cancer. Despite this, protection of the gonads from pelvic radiation and storage of the gametes and embryos should also be considered as the alternative options (29 ve 31 ).

The new oncology treatments provide increasing number of cancer patients, particularly the young patients, with the chance of leading a normal life. Such treatments confer them the opportunity of having children as well. Correspondingly, increasing achievements in assisted reproductive techniques have also boosted hopes; and belief that cancer-induced and cancer treatment-induced infertility can be solved through medical approaches has been conceived. A significant proportion of young cancer patients state that they cannot find the opportunity to discuss fertility sufficiently; some attribute this to cancer while others attribute this situation to the scarcity of time $(29,32)$. Most of the time, it is too late. Moreover, recommendations related to fertility preservation are often offered in an inappropriate manner and this overlaps with the period when the patients are overly confused with regard to their cancer treatments. This destabilizes the patients as a consequence. In some cases, a number of choices such as removing the ovarian tissue, breaking it up and implanting it under the skin have been developed; yet it has been observed that the right differentiation has not been made in terms of the presentation of these options. What is more, such works have been popularized dramatically by the media before the scientific findings have been revealed (33).

Freezing the ovarian tissue, urgent IVF, in vitro maturation (IVM) and ovarian suppression by GnRH analogues and random start ovarian stimulations can be used as several methods for preserving fertility $(34,35)$. An important issue worthy of being taken into consideration at this point is the necessity of having an immediate discussion about both of the matters, which are cancer and preservation of fecundity as well. It is for this reason that cancer and fertility-preservation matters require to be managed by adopting a multidisciplinary perception, putting forth all the possible choices and determining the most appropriate approach then. What is desired indeed is to form a "task force" in local medical committees that are competent in cancer and fecundity. For such local committees to be formed, it is necessary that organizations that are capable of administering all the aforementioned fertility-preserving 
approaches exist. There are not adequate numbers of centers on in vitro maturation and this situation seems to be a deficit. One of the important functions of task forces is that they follow up the studies on fertility preservation closely.

It is required to set the priorities and decide on whether to have a narrow or broad dimension for the formation of a committed "task force". While a task force with an inadequate dimension would fail to satisfy offering services, a broad task force would experience difficulties in offering treatment options with a required level of sensitivity due to their increasing work burden. A sample study for such a task force was put into practice in Switzerland, in a French speaking region of the country. An area with 1.5 million residents was chosen to be the pilot region (36). The number of breast cancer patients (the most frequently encountered type of cancer that develops in one year and is seen among young women) was calculated. The results showed that 115 new patients among the age group below 45 in such population density emerged every year. Assuming that discussions about fertility preservation are made with the 50\%-70\% of the young cancer patients, it has been foreseen that the task force could only have contact with 60-85 of the patients. With the premise that breast cancer patients account for $40 \%$ of the young cancer patients, it can be predicted that the total number of patients that the task force can see per year would be between the range of 15-210 patients (when 1.5 million people are taken as the basis). Based on such data, it is concluded that such numbers could be at the threshold of low number for the IVF centers and the ideal target population density should be between 2-7 million in this regard (33).

At this point, this question may be addressed: do such patients become completely infertile or could they have a chance of spontaneous pregnancy?

The possibilities of natural conception through fertility-preservation approaches should be discussed with all cancer patients. It is also important to act in line with the cancer type. As a general piece of information, it is known that primordial follicles are more resistant to chemotherapy compared to developing follicles. This situation also provides an explanation of the fact that the patients have their menstruation $6-9$ months after the chemotherapy. This period overlaps with the new development phase of primordial follicles from the primordial follicle pool.

Hematologic malignancies and particularly Hodgkin lymphoma come to mind when young age cancers are at stake; however, breast cancer appears to be the mostly encountered cancer during the reproductive period (at $13 \%$ during the reproductive period of a person) due to its prevalence (37). It is possible to observe spontaneous pregnancies following the breast cancer treatment owing to the nature of chemotherapies used in breast cancer. For this reason, it is of importance to bear in mind the high probabilities of conception in patients with breast cancer prior to identifying the fertility-preserving approaches. In addition to this, the fact that there will be difference between menstruating and fertility periods should not be disregarded. Thus, checking AFC and AMH before cancer treatment and performing a reevaluation after the treatment can ensure the revealing of the dimension of ovarian reserve loss (38).

Despite having such possibilities, it is quite difficult to know who would be able to get pregnant and who would not be able to do so. Yet, ensuring of fecundity is possible 
only through conception. Furthermore, chemotherapy agents that are used could have long-term effects and they may lead to infertility or menopause (39).

Ovarian functions and fecundity ameliorate following the chemotherapy in breast cancer cases. It is generally seen in women in their 30's and there are 3-6 weeks of time period between surgery and chemotherapy. For these reasons, the possibility of performing an urgent IVF in the intermittent period emerges. Thus, it is important to avoid oophorectomy and grafting of ovarian tissue as far as possible for patients at this age group, particularly in cases of breast cancer. Unilateral oophorectomy may cause FSH increase and premature menopause during the 30's (40). Instead, administration of an urgent IVF and embryo freezing procedure could be opted for. In this period of 3-6 weeks, using aromatase inhibitors in ovarian stimulation also increases the probability of retrieving eggs and reduces exposure to estrogen (41). Another point to be paid attention to is that such an administration can be performed only on cases in which the patient first underwent surgery, afterwards chemotherapy. For cases with administration of neoadjuvant chemotherapy and later surgery, such a treatment would not be preferred.

\section{Current strategies for fertility preservation in females}

According to the data of American Cancer Society (ACS), it is predicted that new cancer diagnosis was made for 790000 women in 2012 (42). $83 \%$ of the women aged below 45 diagnosed with cancer between 2002-2012 maintained their lives (43). The treatment of many types of cancer in the reproductive period of an individual involves either the removal of reproductive organs through surgery or the use of cytotoxic medications that partially or entirely affect the reproductive functions. Ovaries act as the target organs for cytotoxic treatments, and primordial follicles are affected directly by these treatments (44). The prime reasons why ovarian insufficiency develops after cancer treatments are dependent on the ovary reserve of the patient prior to the onset of the treatment, the dose of the treatment agent used and its duration (45). Entire ovarian tissue freezing, ovarian cortical tissue freezing, ovarian transplantation, oocyte and embryo freezing as well as using GnRH analogues happen to be several treatments planned. However, the treatment approach recommended by the American Society for Reproductive Medicine (ASRM) is the cryopreservation of the oocytes or embryos that are obtained by in vitro fertilization method $(46,47)$. Other approaches are still regarded as experimental treatments. Controlled ovarian stimulation $(\mathrm{COS} / \mathrm{COH})$ is an approach of treatment that is preferred owing to its high success and efficacy rates (48). Many of the patients start their treatment without receiving any consultation about fertility preservation despite the time elapsed. Afterwards, cancer survivors have expectations about fertility. In the above parts of this review, treatment choices for those patients who are consulted and have contact with reproductive endocrinology and infertility specialists have been presented. Another point in question is how can the patients whose cancer treatments proved to be successful and targeted treatment option has been used be treated when they have expectations about fertility? Cases of targeted cancer therapy enable the maintaining of cancer treatments while being able to sustain fertility-preserving approaches.

Freezing the oocytes or embryos could be used for postpubertal patients and patients who are married. The possibility of doing this procedure is dependent on the following 
factors: the existence of an IVF center, having the competency of performing ovarian stimulation to the cancer patients and being experienced in good embryo development and cryopreservation. This approach is no longer considered to be an experimental one (46). Data related to the egg freezing of the cancer patients and their pregnancies afterwards are highly limited. In recent years, randomized controlled studies where pregnancies achieved through oocyte vitrification are compared with fresh oocyte embryo transfers have reported that similar results have been obtained as to the implantation and pregnancy rates (48-50). For the time being, ovarian stimulation for the embryo or mature oocyte freezing is considered to be the most appropriate strategy for attaining pregnancy. This can be tried out if the following conditions are present: the patient does not have a situation which would prevent the collection of bocyte, there is available time for the ovarian stimulation, the patient has a medical condition that is fit for this procedure and it is safe to do ovarian stimulation. The most important problem at stake is that the patient is not on her menstrual period and the possibility that the treatment may cause delay. The number of antral follicles (AFC), antimullerian hormone levels (AMH) and FSH levels have importance in determining the gonadotropin dose to be used (51). Short term gonadotropin antagonist treatments could be preferred. Yet, in a situation where menstruation does not start, a mode of treatment independent of menstrual cycle and that is even on luteal phase can be planned through random start protocols in order to avoid time loss $(52,53)$. By taking into consideration the fact that the patients have the possibility of receiving treatment for themselves only, the most suitable treatment choice should be administered. On the other hand, it is important to avoid OHSS The use of agonist trigger in antagonist cycles could be of benefit to serve this purpose (54).

Medical or surgical treatments can be done conservatively, particularly for early phase tumors and borderline tumors in women; thus fertility is preserved in this way. For the patients on whom local pelvic radiation therapy will be administered, as a result of ovarian transposition operation, ovary can be detracted from the area where radiation therapy will have impact. In this way, it could be possible to preserve fertility. If it is planned to collect eggs following such an operation, transabdominal collection would be more apt.

All the treatments conducted for the purpose of fertility preservation other than those already specified are considered to be experimental treatments, this is the case so particularly in the USA. Treatments that fall into experimental categories are stated below:
A) Ovarian tissue freezing
B) In vitro oocyte maturation (IVM)
C) Ovarian suppression by GnRH analogues

In some specific cases, there may exist an available time interval following the surgery of the patients, this time frame extends up until postoperative chemotherapy. For example, in breast cancer cases that have been through lumpectomy or mastectomy, there is a long period of time for chemotherapy following the surgery. The major concern here is the hypoestrogenic effect that will be induced by ovarian stimulation to be performed and also the emergence of adverse effects in the course of the disease due to ovarian stimulation. It is for this reason that gonadotropins can be used along 
with an aromatase inhibitor on such patients rather than being used solely (55). Similarly, administration of bilateral prophylactic salpingo-oophorectomy (BSO) could be recommended for cases that are BRCA mutation carriers (56). Ideally, BSO should be performed after fertility comes to an end; however, there exist alternative options for such patients like the collecting of oocyte intermittently and freezing the embryo or oocyte. In addition, PGD could be administered on these patients in the future and through embryo transfer with BRCA discarded, it would be possible to prevent passing on to the generations. Ovarian tissue transplantation is not recommended to BRCA mutation carriers.

Hematologic malignancies pose a serious problem to preserving fertility considering the thought that the course of the disease is severe and even a minor surgical intervention could cause serious deterioration in the blood picture. Furthermore, even if the ovarian tissue is removed and can be transplanted subsequently, it is important not to overlook the probability that leukemia might be implanted once again through this tissue $(57,58)$. Even though lymphoma patients are more appropriate ones for fertility preservation, consultation is not recommended that much at the beginning since the treatments administered have minor gonadotoxic effects. For this reason, referral of the patients in hematologic malignancies is done in cases of recurrence, or after chemotherapy or induction treatment, or prior to stem cell transplantation. Thus, the patients have already started gonadotoxic treatment in hematologic malignancies (59).

The most sensitive group in fertility preservation is the children and adolescent patient groups. Determination of the appropriate strategy for these patients should be considered very carefully. It is harder to talk about this issue with the patients and their families than what is anticipated. Besides this, fertility-preserving infrastructure does not exist or fail to be sufficient in children hospitals. It is possible to perform oocyte collection in postpubertal girls aged below 18 . This option is possible for peripubertal adolescents as well. IVMcan also be recommended to such population.

\section{Other indications for fertility preservation}

Fertility preservation is not only restricted to cancer patients but can also be used in some other medical conditions (60). Indications of fertility preservation other than cancer are listed below:

a) Premature ovarian failure (POF)

b) Chromosomal and Genetic abnormalities (Turner Syndrome, 47, XXX, Fragile

$\mathrm{X}$ GALT enzyme or FSH receptor Mutation)

c) Autoimmune Diseases (Thyroid, polyglandular, multiple endocrine)

d) Environmental factors (Malaria, varicella, shigella may cause POF)

e) Surgical menopause (benign ovarian disease, prophlactic oophorectomy)

f) Cytotoxic agents for hematological and autoimmune diseases

g) Postponing fertility/Social indications

\section{Fertility preservation strategies in males}

When compared with female cases, fertility preservation in males is slightly easier. Sperm freezing procedure does not require any treatment beforehand, it does not cause 
time loss for the patient, and it is a simple procedure of giving sample that is repeatable as well. Sperm cryopreservation is a male fertility-preservation method that is recommended on standard basis. It is important that semen sample has already been retrieved prior to chemotherapy and radiation therapy. At least 3 samples of semen are to be taken ideally and the storage should be performed by using many numbers of vials for the cryopreservation procedure. It could be hard to provide sample in young adults so it is important that they give the sample in an environment that is peaceful and comfortable. There are other challenges regarding the provision of sample, which are anxiety, fatigue, pain, additional morbidities, neurological problems, diabetes mellitus and hypogonadism. In such cases, the following approaches are recommended to be used for obtaining the samples:

a) Phosphodiesterase type 5 (PDE-5) which is generally used in erectile dysfunctions but it is preferred in situations where giving sample is hard(61)

b) Penile vibratory stimulation

c) Electroejaculation

d) Retrograde sperm collection and cryopreservation

e) Cryopreservation of sperms obtained by surgery

$\mathrm{GnRh}$ analogue treatment and storing testicular tissue of prepubertal period for male fertility preservation are still considered to be experimental $(62,63)$.

When the effects of cancer on male fertility are analyzed, $30 \%$ of the testicular cancer cases demonstrate semen anomalies at the onset. Interestingly enough, semen

problems at such a scale are also seen in cases that encounter other types of cancer at a young age. In a study conducted on 158 patients (aged 16-52) with Hodgkin lymphoma, it is revealed that $111(70 \%)$ of the patients had degeneration in their semen parameters (64). Germinal epithelium is a highly sensitive tissue; and it is chemo-radiosensitive (65). Major subfertility is observed in cases where alkylating agents and radiation therapy are received. In radiation therapy administered with a dose that exceeds 4Gy, permanent fertility loss, namely sterility is observed (20). Moreover, the sperm tests that show a downward trend within a period of 3-6 months after chemotherapy and radiation therapy may start to get better slowly. When 2 years elapse following the treatment, spermatogenesis relapses in several phases with a probability of $97 \%$ and $94 \%$ after chemotherapy and radiation therapy, respectively (66). Azoospermia develops with $59 \%$ in the patients who are treated due to lymphoma; and its relapse duration is much longer (45 months) (67). Testicular somatic cells, namely sertoli and leydig cells, are more resistant than germ cells. Yet, alkylating agents or agents similar to those may affect sperm production by damaging these cells (68).

Figure-1 Decision tree for male oncofertility patient (with the permission of Theressa K Woodruff)

Near here

Figure-2 Decision tree for female oncofertility patient (with the permission of Theressa K Woodruff)

Near here

\section{Setting up a nationwide fertility preservation/oncofertility program in Turkey: Recommendations}


The following recommendations have been put forth for preserving fertility and efficacy of oncofertility system concerning adolescents and young cancer patients:

a) Dissemination of information, knowledge, training and available data,

b) Developing relations with the external centers, and being in contact with all the oncology units, family physicians and nurses in places where multidisciplinary approach does not exist,

c) Establishing male, female fertility-preservation consultations and psychosocial support mechanisms through internal referral system,

d) Generating referral forms, enabling the admission of patients from internal referral systems in other places,

e) Internal and external referral systems keep in contact with one another periodically, hold meetings and perform professional updates as well,

f) Having a sound database software,

g) Determining multimodal approaches that would offer maximum benefit, physicians having discussions about these matters with their patients.

It is also very important to develop a record system related to fertility-preservation approaches administered to cancer patients. It is recommended that such records be registered together with general ones where ART data are collected across the country. The treatment approach administered on cancer type, rates of taking a baby home and spontaneous pregnancy rates in similar cases are suggested be noted in such records. Local fertility foundations should be involved in lobbying activities along with medical associations and Ministry of Health.

h) There should be liaison / contact points which will serve for the communication needs of the patients so that they can achieve result in a quick manner by accessing the points easily and establishing prompt contact with the relevant physicians as well. Local task forces are also recommended to be established for this purpose.

i) Oncologists, reproductive endocrinologists, urologists and surgeons competent in gonadectomy are required to act as part of an interdisciplinary medical team.

j) As the most important arm of this matter, center of assisted reproductive techniques (IVF centers) competent and experienced in the area should be existent. Such centers are expected to be qualified in fertility-preservation methods, stimulation protocols, oocyte freezing, embryo freezing and in vitro maturation (IVM). Further competenee is also required as regards the freezing of both sperm and testicular tissue. There are directives in our country regarding sperm, egg and embryo freezing. Ideally, these centers would be able to perform ovarian and testicular tissue freezing procedures even in prepubertal cases whose informed consent have been obtained. Such procedures are still accepted as experimental ones, though.

k) Support of mental health professionals should be taken in order to overcome the difficulty experienced by young adult, child or premenopausal patients when they are to make a decision. By doing the genetic consultations, patients should be informed about passing the current disease on to next generations genetically. One of the most crucial issues is making the financial situation clear and getting financial consultancy for this process which government does not grant aid. In this way, approaches that will help to curtail costs could be identified.

1) Interdisciplinary collaboration is of crucial importance in fertility preservation. The patients should be referred to a competent reproductive endocrinologist or 
urologist after having a thorough discussion on the situation of the patient. If possible, all patients, including those at premenopausal age and adolescence, should undergo such a mechanism of referral. This is highly important so as to identify the optimal treatment and arrange the timing for fertility preservation. It is also important to eliminate legal and ethical problems along with professional arrangements.

m) When the patient is referred to a reproductive endocrinologist, it is important to discuss at length all the medical and surgical options available for the preservation of fertility. It is also vital to talk about the existence of alternative treatment approaches like donation and adoption which are not legal in our country. The current situation of the patient should definitely be taken into consideration as to the decision. It may not be deemed appropriate to present matters related to fertility preservation to an individual who is too ill to be treated. Potential safety of pregnancy in the future after the cancer treatment should be explained to the patient. Patients whose gametes and embryos are planned to be frozen should definitely be advised to go through scans of infectious diseases. Concerning patients who make the decision of freezing gamete, embryo and tissue, what would lie ahead in the future in case of the death of the patient should also be discussed. This discussion should also be documented and recorded. If there is available time, the patient is recommended to meet the physician, nurse and mental counsellor.

\section{Further recommendations for a nationwide fertility preservation program}

1) This organization must be controlled with a registration system by the Ministry of Health of Turkey.

2) It is recommended to be a part of $\mathrm{OC}$ in a country based program

3) A web-based program should be implemented with the aid of OC

4) Societies related to oncofertility may be recommended to organize annual meetings to upgrade the knowledge concerning oncofertility and fertility preservation

5) A nurse training program may be initiated by the Ministry of Health

6) IVF centers experienced in IVM and ovarian tissue freezing need to be recognized and regionally selected centers and their staff must be trained for IVM and ovarian tissue freezing in order to settle regional centers for tissue and gamete freezing.

7) A multidisciplinary approach including oncologists, reproductive endocrinologists, embryologists, genetic specialists, radiologists and specialized nurses and social workers should be arranged for proper fertility preservation counselling.

8) Internationally accepted ovarian stimulation regimens should be implemented for IVF protocols

9) Periodical multidisciplinary team counselling linked with task forces or satellite hospitals to manage the oncofertility patients in an appropriate manner

10) Annual report of the whole country together with registration of every single patient from the centers to the health ministry registration system.

11) Standardization of documents derived from the sources of OC should be carried out.

\section{Concluding Remarks}


Although there are centers dealing with oncofertility and fertility preservation individually,there is a strong necessity to have a nationwide registry gathering all informations from the selected and accredited centers disseminated all major regions in Turkey.For this, acolaborative work up should be started with oncology societies, gynecology and infertility societies and of course the society of clinical embryology which then may be connected to global oncofertility consortium to develop new strategies together with already experienced world centers which have been dealing with fertility preservation voluntariliy for many years.

Acknowledgement: Authors of this review would like thank by heart to Teresa $\mathrm{K}$ Woodruff M.D,Professor,PhD , Dean, The Graduate School and Associate Provost for Graduate Education Northwestern University,Chicago,Illinois,USA and The Watkins Professor of Obstetrics and Gynecology, Feinberg School of Medicine,Chicago,Illinois, USA and Lauren AtamanM.D,Professor Administrative Director, Oncofertility Consortium Research Project Manager OB/GYN, Feinberg School of Medicine Northwestern University,Chicago,Illinois, USA for their great support for the make-up of this study and kind acceptance of the figures to be used in this review.

\section{References}

1. Gracia CR, Sammel MD, Freeman E, et al. Assessing The Impact Of Cancer Therapies On Ovarian Reserve. Fertility and sterility. 2012;97(1):134-40.e1. doi:10.1016/j.fertnstert.2011.10.040.

2. West ER, Zelinski MB, Kondapalli LA, et al. Preserving Female Fertility Following Cancer Treatment: Current Options and Future Possibilities. Pediatric blood \& cancer. 2009;53 (2):289-295. doi:10.1002/pbc.21999.

3. Lauren M. Ataman, Jhenifer K. et al. Creating a Global Community of Practice for Oncofertility. Journal of Global Oncology 2016 2:2, 83-96. doi: $10.1200 /$ jgo.2015.000307

4. Von Wolff M, Germeyer A, Liebenthron J, Korell M, Nawroth F. Practical recommendations for fertility preservation in women by the FertiPROTEKT network. Part II: fertility preservation techniques. Archives of Gynecology and Obstetrics. 2018; 297 (1):257-267. doi:10.1007/s00404-017-4595-2.

5. González C, Boada M, Devesa M, Veiga A. Concise Review: Fertility Preservation: An Update.Stem Cells Translational Medicine. 2012;1(9):668-672. doi:10.5966/sctm.2012-0076.

6. Gardino SL, Jeruss JS, Woodruff TK. Using decision trees to enhance interdisciplinary team work: the case of oncofertility. Journal of Assisted Reproduction and Genetics. 2010;27(5):227-231. doi:10.1007/s10815-010-9413-8. 7. Eric J. Forman, M.D., Carey K. Anders, M.D., and Millie A. Behera, M.D. Pilot Survey of Oncologists Regarding Treatment-Related Infertility and Fertility Preservation in Female Cancer Patients J Reprod Med. 2009 April ; 54(4): 203-207. 
8. Küçük M, Yavaşoğlu İ, Bolaman AZ, Kadıköylü G. Knowledge, Attitudes, and Practices of Hematologists Regarding Fertility Preservation in Turkey. Turkish Journal of Hematology. 2013;30(3):269-274. doi:10.4274/Tjh.2012.0015.

9. Loren AW, Brazauskas R, Chow EJ, et al. PHYSICIAN PERCEPTIONS AND PRACTICE PATTERNS REGARDING FERTILITY PRESERVATION IN HEMATOPOIETIC CELL TRANSPLANT RECIPIENTS. Bone marrow transplantation. 2013;48(8):1091-1097. doi:10.1038/bmt.2013.13.

10. Forman EJ, Anders CK, Behera MA. A nationwide survey of oncologists regarding treatment-related infertility and fertility preservation in female cancer patients. Fertil Steril. 2010; 94 (5): 1652-6. doi: 10.1016/j.fertnstert.2009.10.008.

11. Hotaling JM, Laufer N, Rosenwaks Z. Introduction: Cancer biomarkers and fertility. Fertil Steril. 2018; 109 (1): 4-5. doi: 10.1016/j.fertnstert.2017.12.009.

12. Hanson BM, Eisenberg ML, Hotaling JM. Male infertility: a biomarker of individual and familial cancer risk. Fertil Steril. 2018 Jan;109(1):6-19. doi: 10.1016/j.fertnstert.2017.11.005.

13. Nagirnaja L, Aston KI, Conrad DF. Genetic intersection of male infertility and cancer.

Fertil Steril. 2018; 109 (1): 20-26. doi: 10.1016/j.fertnstert.2017.10.028.

14. EmmaJames B.S.Timothy G.J. Epigenetics, infertility, and cancer: future directions. Fertil Steril. 2018; 109 (1): 27-32. doi: 10.1016/j.fertnstert.2017.11.006.

15. CancerStats Incidence 2008 - UK. Cancer Research UK 2011 Registered charity in England and Wales (1089464) and Scotland (SC041666).

16. Gatta G, Zigon G, Capocaccia R, Coebergh JW, Desandes E, Kaatsch P, Pastore G, Peris-Bonet R, Stiller CA; EUROCARE Working Group. Survival of European children and young adults with cancer diagnosed 1995-2002. Eur J Cancer. 2009; 45 (6): 992-1005. doi: 10.1016/j.ejca.200811.042.

17.Donnez J , Martinez-Madrid B, Jadoul P, Van Langendonckt A, Demylle D, Dolmans MM.Ovarian tissue cryopreservation and transplantation: a review. Hum Reprod Update. 2006 Sep-Oct;12(5):519-35. Epub 2006 Jul 18.

18. K.Diedricha, J.M. Fauser, P.Devroey. Cancer and fertility: strategies to preserve fertility. RBM Online. 2011, 22 (3): 232-48. doi: 10.1016/j.rbmo.2010.11.001

19. Critchley HO, Wallace WH. Impact of cancer treatment on uterine function. J Natl Cancer Inst Monogr.2005;(34):64-8 . doi:10.1093/jncimonographs/lgi022

20. Wallace WH, et al. Predicting age of ovarian failure after radiation to a field that includes the oyaries. Int J Radiat Oncol Biol Phys. 2005; 62 (3): 738-44. doi: 10.1016/j.jurobp.2004.11.038

21. Green DM, et al. Pregnancy outcome of female survivors of childhood cancer: a report from the Childhood Cancer Survivor Study. Am J Obstet Gynecol. 2002;187(4):1070-80. doi: 10.1067/mob.2002.126643

22. Wallace WH, Thomson AB, Kelsey TW. The radiosensitivity of the human oocyte. Hum Reprod. 2003;18(1):117-21.

23.Blumenfeld Z, von Wolff M. GnRH-analogues and oral contraceptives for fertility preservation in women during chemotherapy. Hum Reprod Update. 2008 NovDec;14(6):543-52. doi: 10.1093/humupd/dmn022. 
24 Petrek JA, Naughton MJ, Case LD, et al. Incidence, time course, and determinants of menstrual bleeding after breast cancer treatment: a prospective study. J Clin Oncol. 2006;24:1045-1051. doi:10.1200/JCO.2005.03.3969.

25. Broekmans FJ, Visser JA, Laven JS, Broer SL, Themmen AP, Fauser BC. AntiMüllerian hormone and ovarian dysfunction. Trends Endocrinol Metab. 2008; 19 (9): 340-7. doi: 10.1016/j.tem.2008.08.002.

26. Meirow D, Nugent D. The effects of radiotherapy and chemotherapy on female reproduction. Hum Reprod Update. 2001;7:535-43.

27. Anderson RA, Themmen AP, Al-Qahtani A, Groome NP, Cameron DA. The effects of chemotherapy and long-term gonadotrophin suppression on the ovarian reserve in premenopausal women with breast cancer. Hum Reprod. 2006;21(10):258392. doi: 10.1093/humrep/del201

28. Donnez J', Dolmans MM, Martinez-Madrid B, Demylle D, Van Langendonckt A. The role of cryopreservation for women prior to treatment of malignancy Curr Opin Obstet Gynecol. 2005 Aug;17(4):333-8.

29. Partridge AH, Gelber S, Peppercorn J, Sampson E, Knudsen K, Laufer M, et al. Web-based survey of fertility issues in young women with breast cancer. J Clin Oncol. 2004 Oct 15;22(20):4174-83. do1: 10.1200/JCO.2004.01.159

30. Ethics Committee of the American Society for Reproductive Medicine. Fertility preservation and reproduction in cancer patients. Fertil Steril. 2005;83 (6): 1622-8. doi: 10.1016/j.fertnstert.2005.03.013.

31. Eskander RN, Randall LM, Berman ML, Tewari KS, Disaia PJ, Bristow RE. Fertility preserving options in patients with gynecologic malignancies. American journal of obstetrics and gynecology. 2011;205(2):103-110. doi:10.1016/j.ajog.2011.01.025.

32. Partridge AH, Gelber S, Peppercom J, Ginsburg E, Sampson E, Rosenberg R, Przypyszny M, Winer EP. Fertility and menopausal outcomes in young breast cancer survivors. Clin Breast Cancer. 2008 Feb;8(1):65-9. doi: 10.3816/CBC.2008.n.004. 33. de Ziegler D, Streuli I, Vasilopoulos I, Decanter C, This P, Chapron C. Cancer and fecundity issues mandate a multidisciplinary approach. Fertil Steril. 2010 Feb;93(3):691-6. dor: 10.1016/j.fertnstert.2008.12.028.

34. Hatırnaz Ş, Ata B, Saynur Hatırnaz E, Dahan MH, Tannus S, Tan J, Tan SL. Oocyte in vitro maturation: A sytematic review.Turk J Obstet Gynecol. 2018 Jun;15(2):112-125. doi: 10.4274/tjod.23911. Epub 2018 Jun 21. Review.

35. Hatirnaz S, Basbug A, Akarsu S, Hatirnaz E, Demirci H, Dahan MH. Outcomes of random start versus clomiphene citrate and gonadotropin cycles in occult premature ovarian insufficiency patients, refusing oocyte donation: a retrospective cohort study.Gynecol Endocrinol. 2018 May 30:1-6. doi: 10.1080/09513590.2018.1473361. [Epub ahead of print]

36.Zaman K, Ambrosetti A, Perey L, Jeanneret-Sozzi W, Delaloye JF, De Ziegler D. Breast cancer in young women: adjuvant therapy and fertility. Rev Med Suisse. 2007 May 23;3(112):1298-1300, 1302, 1304.

37. Armstrong K, Eisen A, Weber B. Assessing the risk of breast cancer.N Engl J Med 2000;342:564-71. doi: 10.1056/NEJM200002243420807

38. Decanter C, Morschhauser F, Pigny P, Lefebvre C, Gallo C, Dewailly D. Anti-

Müllerian hormone follow-up in young women treated by chemotherapy for 
lymphoma: preliminary results. Reprod Biomed Online. 2010; 20 (2): 280-5. doi: 10.1016/j.rbmo.2009.11.010.

39. De Bruin ML, Huisbrink J, Hauptmann M, et al. Treatment-related risk factors for premature menopause following Hodgkin lymphoma. Blood 2008;111:101-108. doi: 10.1182/blood-2007-05-090225

40. Cramer DW, Xu H, Harlow BL. Does 'incessant' ovulation increase risk for early menopause?. Am J Obstet Gynecol. 1995; 172 (1): 568-73. doi:10.1016/00029378(95)90574-X

41. Azim AA, Costantini-Ferrando M, Lostritto K, Oktay K. Relative potencies of anastrozole and letrozole to suppress estradiol in breast cancer patients undergoing ovarian stimulation before in vitro fertilization. J Clin Endocrinol Metab. 2007; 92 (6): 2197-200. doi: 10.1210/jc.2007-0247.

42. Surveillance, Epidemiology, and EndResults (SEER) Program. SEER*Stat Database: North American Association ofCentral Cancer Registries (NAACCR) Incidence-CiNA Analytic File, 1995-2008, forExpanded Races, custom file with county,ACS Facts \& Figures projection project,North American Association of Central Can-cer Registries. Bethesda, MD: National Can-cer Institute, Division of Cancer Control andPopulation Sciences, Surveillance ResearchProgram, Cancer Statistics Branch; 2011.

43. Howlader N, Noone A-M, Yu M, Cronin KA. Use of Imputed Population-based Cancer Registry Data as a Method of Accounting for Missing Information:

Application to Estrogen Receptor Status for Breast Cancer. American Journal of Epidemiology . 2012;176(4):347-356. doi:10.1093/aje/kwr512.

44. Rodriguez-Wallberg KA, Oktay K. Recentadvances in oocyte and ovarian tissue cryopreservation and transplantation. Best practice \& research Clinical obstetrics \& gynaecology. 2012;26(3):391-405. dor.10.1016/j.bpobgyn.2012.01.001.

45_Meirow D, Nugent D. The effects of radiotherapy and chemotherapy on female reproduction Hum Reprod Update. 2001 Nov-Dec;7(6):535-43. do1:

10.1093/humupd/7.6.535

46. Fertility preservation in patients undergoing gonadotoxic therapy or gonadectomy: a committee opinionThe Practice Committee of the American Society for Reproductive Medicine American Society for Reproductive Medicine, Birmingham, AlabamaFertility and Sterility® Vol. 100, No. 5, November 2013

47. Cakmak H, Rosen MP. Ovarian stimulation in cancer patients. Fertil Steril. 2013 ;99(6):1476-84. doi: 10.1016/j.fertnstert.2013.03.029.

48.Cobo A, Bellver J, Domingo J, Pérez S, Crespo J, Pellicer A, Remohí J. New options in assisted reproduction technology: the Cryotop method of oocyte vitrification. Reprod Biomed Online. 2008; 17 (1): 68-72. doi:10.1016/S14726483(10)60295-7

49. Rienzi L, Romano S, Albricci L, et al. Embryo development of fresh "versus" vitrified metaphase II oocytes after ICSI: a prospective randomized sibling-oocyte study. Human Reproduction. 2010; 25 (1): 66-73. doi:10.1093/humrep/dep346. 50. Parmegiani L, Cognigni GE, Bernardi S. Et al.. Efficiency of aseptic open vitrification and hermetical cryostorage of human oocytes. Reprod Biomed Online. 2011; 23 (4): 505-12. doi: 10.1016/j.rbmo.2011.07.003. 
51. Anderson RA, Anckaert E, Bosch E, Dewailly D, Dunlop CE, Fehr D, Nardo L, Smitz J, Tremellen K, Denk B, Geistanger A, Hund M. Prospective study into the value of the automated Elecsys antimüllerian hormone assay for the assessment of the ovarian growing follicle pool. Fertil Steril. 2015; 103 (4): 1074-1080. doi: 10.1016/j.fertnstert.2015.01.004.

52. Ozkaya E, San Roman G, Oktay K. Luteal phase GnRHa trigger in random start fertility preservation cycles. Journal of Assisted Reproduction and Genetics. 2012;29(6):503-505. doi:10.1007/s10815-012-9752-8.

53. Sönmezer M, Türkçüoğlu I, Coşkun U, Oktay K. Random-start controlled ovarian hyperstimulation for emergency fertility preservation in letrozole cycles. Fertil Steril. 2011 May;95(6):2125.e9-11. doi: 10.1016/j.fertnstert.2011.01.030.

54.von Wolff M, Thaler CJ, Frambach T, Zeeb C, Lawrenz B, Popovici RM,

Strowitzki T. Ovarian stimulation to cryopreserve fertilized oocytes in cancer patients can be started in the luteal phase. Fertil Steril. 2009; 92 (4): 1360-5 10.1016/j.fertnstert.2008.08.011.

55. Madrigrano A, Westphal L, Wapnir I. Egg retrieval with cryopreservation does not delay breast cancer treatment.Am J Surg. 2007; 194 (4); 477-81. doi.org/10.1016/j.amjsurg.2007.06.008.

56. Kauff ND, Domchek SM, Friebel TM, et al. Risk-Reducing SalpingoOophorectomy for the Prevention of BRCA1- and BRCA2-Associated Breast and Gynecologic Cancer: A Multicenter, Prospective Study. Journal of Clinical Oncology. 2008;26(8):1331-1337. doi:10.1200/JCO.2007.13.9626.

57. Dolmans MM, Marinescu C, Saussoy P, VanLangendonckt A, Amorim C, Donnez $\mathrm{J}$.

Reimplantation of cryopreserved ovarian tissue from patients with acute lymphoblastic leukemia is potentially unsafe.Blood.2010; 116 (16): 2908-14. doi: 10.1182/blood2010-01-265751.

58. Meirow D, Hardan I, DorJ, Fridman E. et al. Searching for evidence of disease and malignant cell contamination in ovarian tissue stored from hematologic cancer patients. Hum Reprod. 2008; 23 (5): 1007-13. doi: 10.1093/humrep/den055.

59. Maltaris T, Seufert R, Fischl F. et al. The effect of cancer treatment on female fertility and strategies for preserving fertility. Eur J Obstet Gynecol Reprod Biol. 2007; 130 (2): 148-55. doi:10.1016/j.ejogrb.2006.08.006

60. Gidoni Y, Holzer H, Tulandi T, Tan SL. Fertility preservation in patients with nononcological conditions. Reprod Biomed Online. 2008;16:792-800. doi:

10.1016/S1472-6483(10)60144-7.

61. Tur-Kaspa I, Segal S, Moffa F, Massobrio M, Meltzer S. Viagra for temporary erectile dysfunction during treatments with assisted reproductive technologies. Hum Reprod. 1999;14:1783-1784.

62. Meistrich ML, Shetty G. Hormonal Suppression for Fertility Preservation in Males and Females. Reproduction. 2008; 136 (6): 691-701. doi:10.1530/REP-08-0096. 63. Brook P, Radford J, Shalet S, et al. Isolation of germ cells from human testicular tissue for low temperature storage and autotransplantation. Fertil Steril. 2001;75:269274. doi:10.1016/S0015-0282(00)01721-0

64. Rueffer U, Breuer K, Josting A, Lathan B, Sieber M, Manzke O, Grotenhermen FJ, Tesch H, Bredenfeld H, Koch P, Nisters-Backes H, Wolf J, Engert A, Diehl V. Male 
gonadal dysfunction in patients with Hodgkin's disease prior to treatment. Ann Oncol. $2001 ; 12$ (9): 1307-11.

65. Orwig KE, Schlatt S. Cryopreservation and transplantation of spermatogonia and testicular tissue for preservation of male fertility. J Natl Cancer Inst Monogr. 2005 ; (34): 51-6. doi: 10.1093/jncimonographs/lgi029

66. Cardis E, Krewski D, Boniol M. et al. Estimates of the cancer burden in Europe from radioactive fallout from the Chernobyl accident. Int J Cancer. 2006 Sep 15; 119 (6): 1224-35. doi: 10.1002/ijc.22037

67.Bahadur G, Ozturk O, Muneer A, Wafa R, Ashraf A, Jaman N, Patel S, Oyede AW, Ralph DJ. Semen quality before and after gonadotoxic treatment Hum Reprod. 2005; 20 (3): 774-81. do1: 10.1093/humrep/deh671.

68. Pastink A, Schalet AP, Vreeken C, Parádi E, Eeken JC. The nature of radiationinduced mutations at the white locus of Drosophila melanogaster. Mutat Res. 1987; 177 (1): 101-15. doi:10.1016/0027-5107(87)90026-1. 


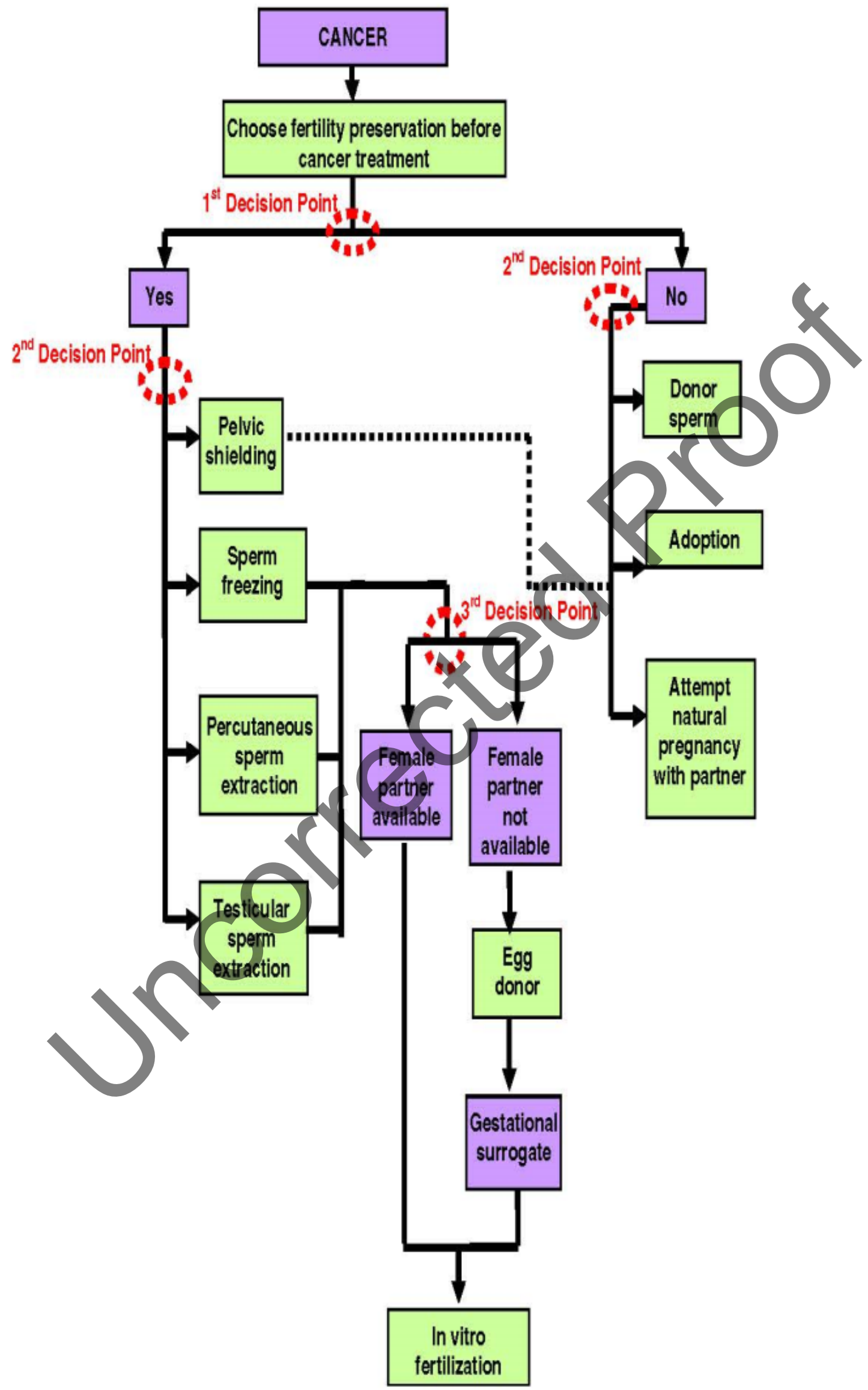




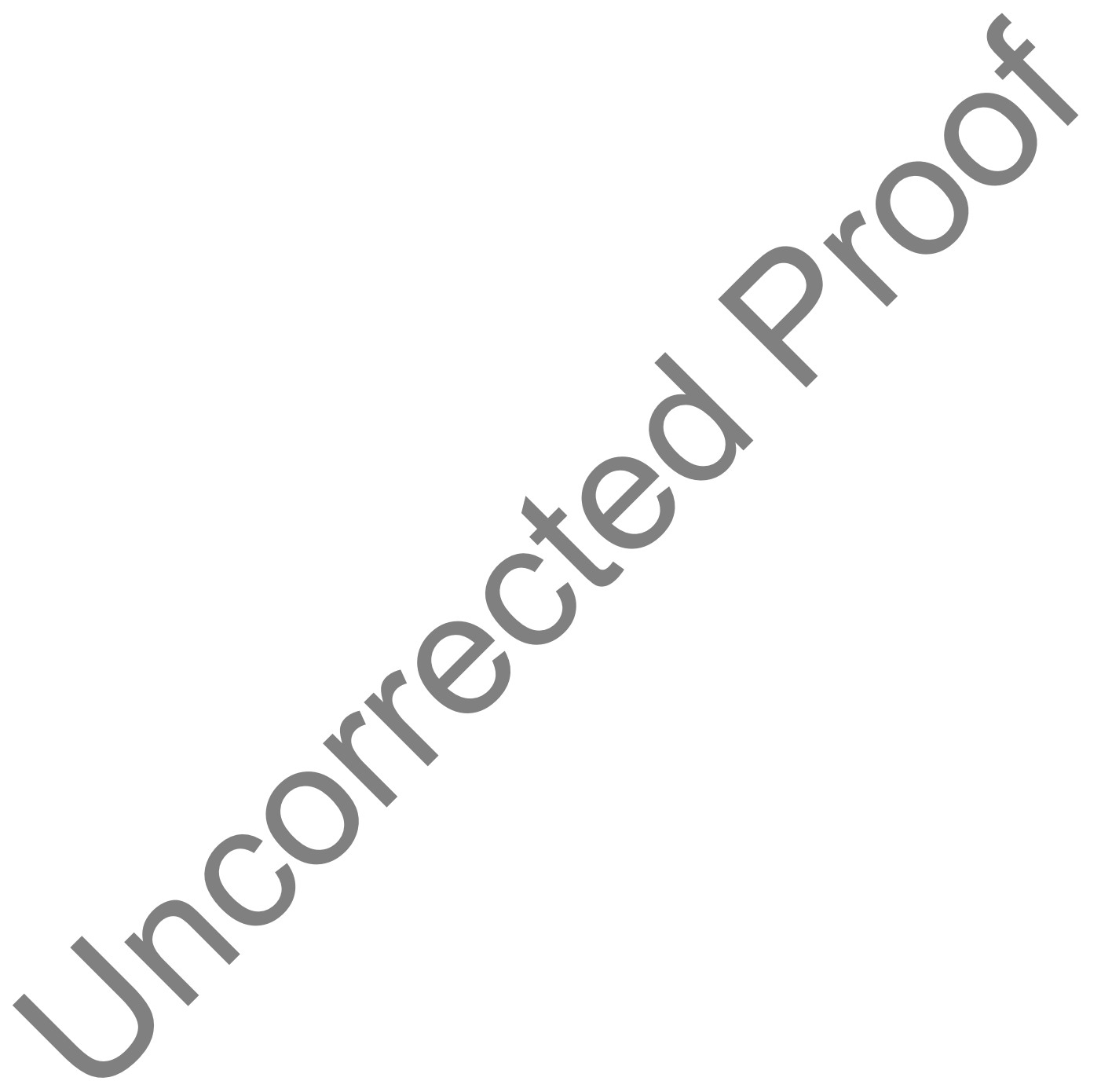




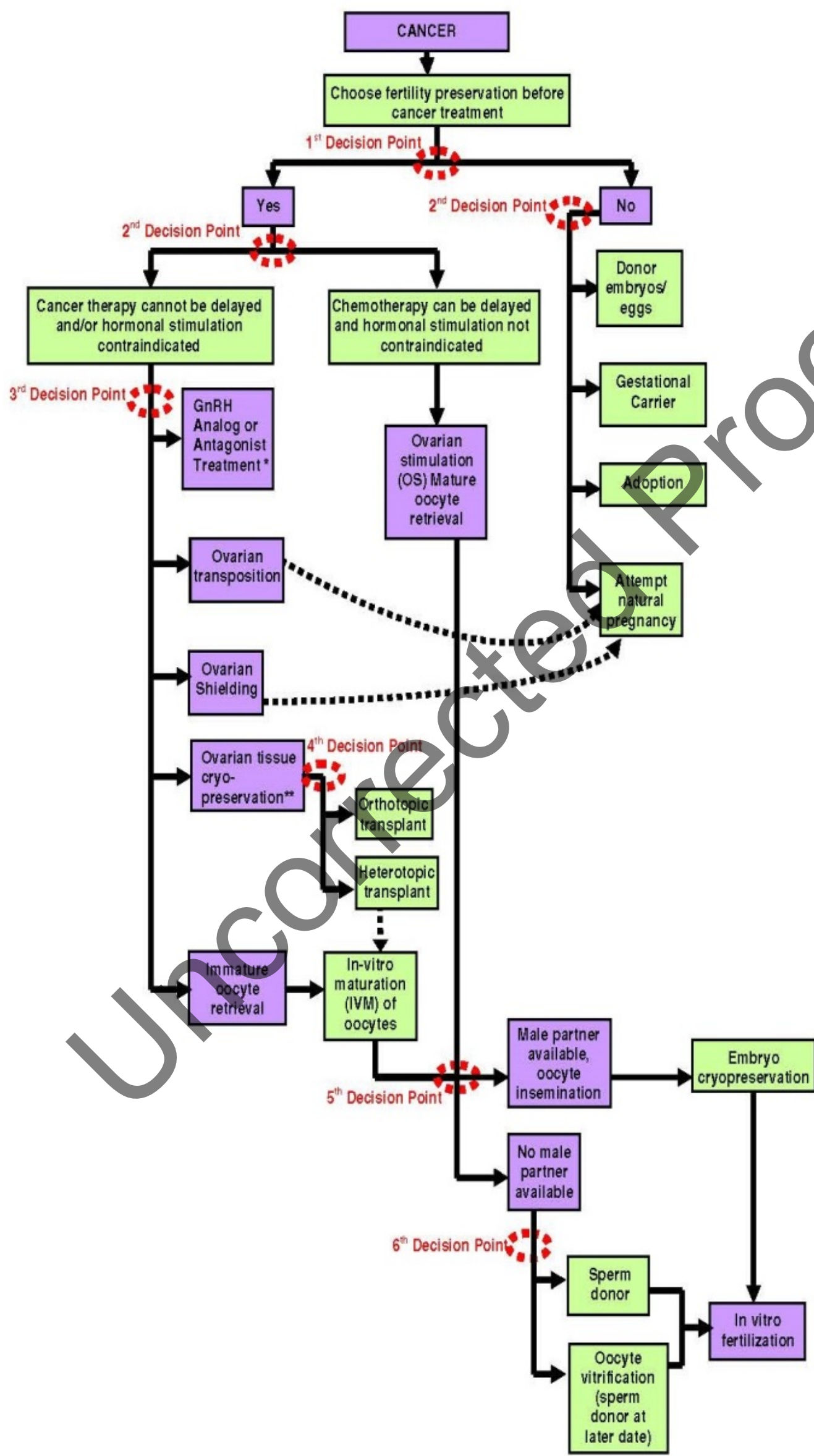




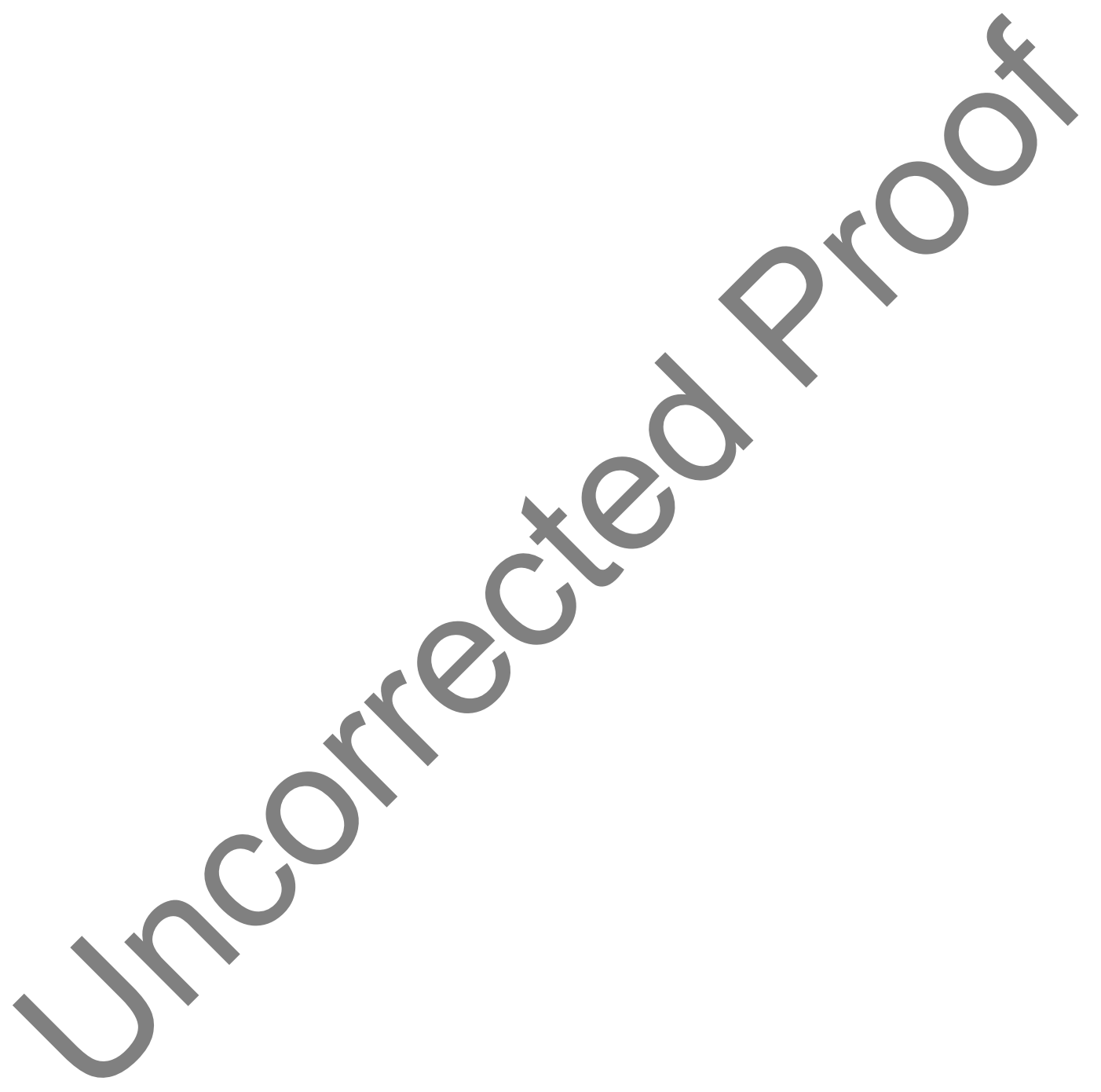

